\title{
Alliesthesia. Up-date of the Word and Concept
}

\author{
Michel Cabanac $^{1 *}$, Laurent Brondel ${ }^{2}$ and Arnaud Cabanac ${ }^{3}$ \\ ${ }^{1}$ Laval University, Quebec, Canada \\ ${ }^{2}$ University of Bourgogne Franche-Comté Dijon, France \\ ${ }^{3}$ Rochebelle School, Quebec, Canada
}

*Corresponding author: Michel Cabanac, Laval University, Quebec, Canada.

To Cite This Article: Michel Cabanac, Laurent Brondel, Arnaud Cabanac. Alliesthesia. Up-date of the Word and Concept. 2020 - 8(4). AJBSR. MS.ID.001293. DOI: 10.34297/AJBSR.2020.08.001293.

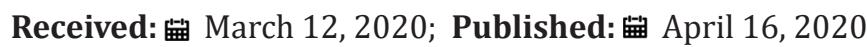

\begin{abstract}
The current dictionary definition for alliesthesia is the hedonic modification of a sensation. The stimuli used to establish this initial definition was skin temperature and sweet tastes. However, accrued experimental evidence shows that changes in hedonicity place also in sensations, and then in other cognitive processes, mental experiences, and in all decision making. These accumulated data render obsolete the previous definition. We propose the following new one: Alliesthesia refers to a modified outcome of the hedonic dimension of any mental process, from sensation to mental performance, and decision making leading to physiological comfort and happiness. Positive alliesthesia is the rise in pleasure or joy or a decrease in displeasure or pain, while negative alliesthesia is the opposite.
\end{abstract}

Keywords: Cognition, Hedonic Experience, Decision-Making

\section{Introduction}

The word alliesthesia was coined in 1971 [1] to describe a change in hedonicity from skin temperature and sweet taste sensations, and is presently defined as: A subjective response to an external stimulus that reflects the internal "homeostasis". Any stimulus capable of Ameliorating the internal homeostasis will be perceived as pleasant; any stimulus that threatens or alters the internal homeostasis would be perceived as unpleasant or painful [2]. Thus, pleasant sensations will lead an individual to seek beneficial behaviors, and unpleasant or painful sensations to avoid noxious or harmful behaviors. This definition was meant to be specific to humans. The concept of alliesthesia led to those of setpoints for the regulations of body temperature and of body weight.

\section{Semantics}

The English word alliesthesia can be found in various other languages (Figure 1). Both the word and the concept appear to have been accepted internationally, butte underlying concept can be recognized in other words and expressions.

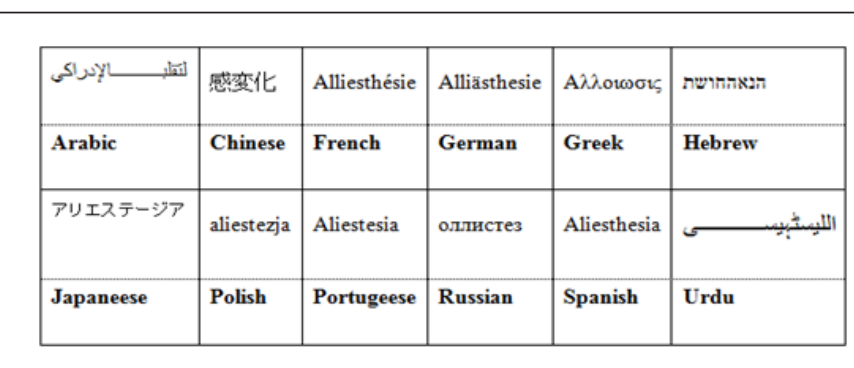

Figure 1: Alliesthesia in various languages.

For instance, sensory-specific satiety [3], has been proposed to describe the decline in the pleasantness of the smell and taste of eaten foods but not of uneaten foods. Subjects not only stop eating a certain food but also describe it as is less palatable. This definition makes sensory-specific satiety a perfect synonym of negative alliesthesia in the case of sensations controlling food intake. Learned taste aversion [4], is the negative hedonicity acquired by a new food when ingestion of that food is followed by illness. Negative alliesthesia also describes this phenomenon. The Garcia 
effect [4], is the opposite: a newly encountered flavor acquires a pleasant quality when followed by pleasant satiety. It is equivalent to positive alliesthesia. Mozart effect. Students reduce thinking time during stressful mathematical tests, and improve pleasantly their results. This 'mystery of music' might be due to the influence of pleasure in overcoming cognitive dissonance [5], Experienced utility [6] is used in economics to describe the pleasure resulting from a beneficial decision. Alliesthesia also describes a subject's hedonic experience to a changing environment or inner state. The Coolidge effect [7], refers to a joke by President Coolidge who, after witnessing a rooster mating repeatedly, pointed out that variety, in terms of new reproductive partners, boosted the male's motivation, arousal, and performance while the hens were quite similar. Happiness is a word most often used to describe maximum positive hedonicity. However, the concept of happiness is ambiguous and misunderstood seeing as it is confounded with joy. Its definition should be indifferent hedonic experience [8]. As joy is only a transient experience of pleasure, the above definition entails that joy is positive alliesthesia.

\section{Toward a general presence in physiology}

Alliesthesia was studied as such, or could be recognized in several published works, not only in simple sensations but also on various physiological functions, the results of which showed an obvious alliesthesia [9]. After Aristotle, Ovsich [10] noticed that pleasures are generated only by what he termed "contact" sensations warmth, pain, taste and skin sensations and that these pleasures can be acquired, i.e. positive alliesthesia. He classified smell as a contact sensation because it can be highly hedonic, even though it picks up remote stimuli. Then, experimental evidence revealed that alliesthesia can take place not only in contact sensations but also in other sensations, resulting from more stimuli than food and temperature initially demonstrated. Such new evidence of sensory alliesthesia were since clearly discerned in published papers or chapters but sometimes not identified as such from rating and psychophysics methods, but were nevertheless obvious [11].

\section{Other tastes}

Were systematically explored, and found under dehydration, hyperthermia and taste manipulation [12]. Hence, Addison's disease raises the liking of salt in patients suffering of a deficit of adrenal glands hormone $[13,14]$.

Such an appetite for salt is a case of therapeutic positive alliesthesia [15]. Glutamate also modifies sweet sensation and hedonicity [16]. Thus, post-feeding satiety made the preceding stimulus pleasant and the insulin-induced absence of satiety's stimulus-response association from developing. It is likely that such long-term modifications of hedonicity for various stimuli has similarly produced human widespread appreciation for the smell of coffee or tea [17].The coffee flavor precedes the post-feeding mood- altering effect of positive alliethesia results in a pleasant dimension for caffeine coffee.

\section{An acidity}

pH 3.5 is usually described as unpleasant. However, sourness tasted better when added with a sugar concentration of about 0.4 mole.l-1. At a same pH, sweet sensation from sugar tasted best at concentration about2.0 mole.l-1 [18]. Also, tasting sour taste was lengthened i.e. negative alliesthesia, by adding a fifth flavor, umami to the four basic tastes [19]. Such fluctuating taste is a case of alliesthesia.

\section{Drugs and hormones}

Estrogen seems to adjust people's ponderostat (body weight set-point) downward whereas progesterone seems to adjust it upward which is direct ad hoc food alliesthesia [20]. These hedonic responses take place in animals also. The facial responses of female rats to tasty stimuli change cyclically with their hormonal status [21]. D-Fenfluramine a drug used to reduce appetite of overweight human patients, works through alliesthesia as judged from taste reactivity measurements [22]. Furthermore, in rats, gustatory alliesthesia has been produced pharmacologically when their body weight set-point was lowered by the drug [23].

Coffee taste, although usually described as unpleasant at first experience, acquisition of liking likely proceeds from a post ingestive influence of caffeine on operant conditioning learning [24]. This process may be one of several contributing to addiction, and it may be amenable to pharmacological intervention. Insulin, that lowers blood glucose, injected into a rat while presenting it with new food marked with a strong odor, such as menthol or eucalyptol, suppresses the meal satiation effects. The insulin-treated rats with unpleasant hypoglycemia now avoid eating the scented food [25] which is clearly negative alliesthesia for the ad hoc new flavors.

Alliesthesia for alcohol took place when Male Wistar rats were allowed to self-administer alcohol vapor for $8 \mathrm{~h} /$ day. Anxiety-like behavior, somatic signs of withdrawal, and hyperalgesia were assessed during acute withdrawal [26].

Nitrous oxide exposure entails drop of temperature regulatory set-point (anapyrexia). To defend that lower set-point, rats lowered their skin temperature preference, i.e..a negative alliesthesia forwarm skin sensation (Repeated nitrous oxide exposure in rats causes a thermoregulatory sign-reversal with concurrentactivation of opposing thermoregulatory effectors [27].

\section{Pain}

In human subjects under hypnosis, pain was described, but displeasure was drastically diminished [29], this amounts to positive alliesthesia. In another experiment, pain was experienced but better tolerated by subjects when the stimulus was pitted against money in a conflict of motivations [29]. 


\section{Integrated complex sensory inputs. Muscular exercise}

Aside from simple sensations, integrated complex sensory inputs, such as in muscular exercise can generate alliesthesia. On a treadmill, the initially indifferent sensations at rest in lower limbs and chest became progressively unpleasant during work, i.e. negative alliesthesia took place, somewhat independent from muscle work intensity [30]. The same was seen when muscular exercise was pitted against cold discomfort [31]. A characteristic form of alliesthesia for whole-body sensations during exercise has been reported [32-34]. When subjects were asked to quantify their sensation of work intensity and hedonicity while walking, as work intensity rose, sensations of intensity rose from rest at different paces. Alliesthesia was increasingly negative during that work, then at rest became instantly positive. Thoracic mechanical sensation also showed alliesthesia. Hence, at first, ventilation rose from almost no sensation, but in hypercapnia, the lungs appeared to be fuller than they actually were. In normocapnia, the sensation was closer to normal. In sum, this is a case of ventilatory alliesthesia. Then, discomfort of hypercapnia-induced dyspnea took place and led to a slower pace of exercise and restoration to normal sensations and decreased discomfort.

The achievement of multi-sensory visual and thermal positive alliesthesia was also specifically proposed in the making of indoor building comfort [35].

Another multisensory stimulus showing clear-cut negative alliesthesia is a dish of cooked meat entailing complex basic taste sensation, mixed in sensations aroused from complex olfactory, and gravy stimuli [24].

\section{Toward a general presence in psychology: Scholastic performance}

Usually, success in performing school works is hedonically positive. Yet, when associated with Mozart effect, students raised their grades [1].

\section{Looking and hearing. Works of art}

From the producers of works of arts to the consumers of these works, experiments are not needed to show that the fine arts provide innumerable examples of positive as well as negative hedonic experience. Quite often the pleasure that results from interacting with art is acquired through education rather than an innate reaction. Such a time-dependent hedonic experience may result from a simple association with other pleasure or displeasure; this type of acquired pleasure is a case of alliesthesia. As seen in its definition [5], Mozart effect influence of music is a case of alliesthesia in school performance. Many other cases of alliesthesia can be recognized in simple vision, and some may be often the visual signal is complex and is an acquired mechanism. Infant wild apes, but not reared ones, show fright on seeing a snake, with no social contamination to explain this acquired displeasure [36]. In humans, the sight of young nubile faces is pleasurable [37].In the Coolidge effect, alliesthesia both negative and positive, can be found also from visual and auditory sensations [38].These hedonic experiences from vision and hearing can be culturally learned, when these sensations are hedonically indifferent on first exposure, through a chain of mental associations with other pleasures. Such acquisition leads to a hedonic modification [39,40]. For example, visual pleasure is aroused when subject's see images of appetizing food while on an empty stomach but not from the same stimuli when well fed [41]. Further, depending on the emotion being expressed watching faces expressing emotions, can be pleasant or unpleasant [42]. In addition, looking threw a can may be pleasant or unpleasant according to water transparency, a characteristic quality of water, looking is better perceived by dehydrated than by normally hydrated subjects [43]. Also, observers perceive the same photos of human faces as pleasant or unpleasant according to the cultural context surrounding the photo presentation. Cloth color preference in the evening under the influence of different light intensities during the daytime [44], and men prefer to look at female faces rather than at masculine ones [45].

Thus, when systematically looked for, alliesthesia can be found in visual and auditory sensations that originate from the environmental signals. It follows that, alliesthesia when defined in, can take place in any sensation from sensory input including sex and pain [46].

\section{Sexual signals}

The Coolidge effect may be at work in human's sexual arousal in a way similar to sensory specific satiety in food intake process. In both cases, alliesthesia is produced by peripheral stimuli. A process similar to that observed in the rooster, whose stimuli changed with each new partner, might be at work in sexual satiety and hunger/satiety in humans and monkeys [47]. Vaginal odor and its hedonic component are described as less intense at the time of ovulation [48], showed a sex difference in the perception of the odor of exaltolide, a highly musky substance. Only adult women perceive this odor and their sensitivity rises strongly at the time of ovulation. Similarly, women are more sensitive than men to the smell of the male hormone testosterone. These life-long differences depend on the hormonal state of the subjects i.e. at puberty, and, accordingly hedonic intensity may occur at the time of ovulation [49]. These preferences appear at puberty and thus reflect longterm alliesthesia [48].

Additional evidence of sexual alliesthesia comes from the response to pleasurable taste stimuli of female rats that changed cyclically with their hormonal status [50,51]. 


\section{Toward a general presence of alliesthesia in all mental processes}

Because alliesthesia is the basic mechanism in the control of biological behavioral decisions leading to the defense of bodyweight and temperature set-points as well as other biologically useful responses, it is natural to wonder whether alliesthesia could be also the mechanism underlying other decisions that generate pleasure and displeasure. Indeed, behavior is not limited to the service of physiological needs. Because most of our time is actually used for non-physiological tasks, one might ask whether this schema could also encompass curiosity, gambling, love of money, aggressiveness, political decisions and any of a number of other motivations. In other words, in addition to sensory pleasures, does alliesthesia occur in "mental pleasures"? Aside from sensory inputs, innumerable other events take place in the mind. They may be hedonically indifferent, but they are often hedonic. When such is the case, an acquired hedonicity is an alliesthesia. There is evidence that satisfaction with an outcome is positively related not just to the position (i.e. actual level) of the outcome, but also to the displacement (i.e. directional difference) between the current level and a reference level [24].

\section{Curiosity}

There seems to be a fundamental disregard in the human mind for knowledge [52]. However, pleasure is gained when curiosity is satisfied through acquired knowledge [53]. Eagerness to read can be varied according to three higher-order types of motivation, which are the emotional, cognitive, and social ones. There are significant differences in motivation depending on cultural participation as well as demographic variables [54]. Pleasurable responses to initially indifferent stimuli can be learned [55]. This phenomenon is particularly obvious in the perception of certain tastes (i.e. the Garcia effect) and some examples of behavioral response demonstrate that pleasure is not rigid or permanent, which strongly indicates a mechanism of alliesthesia. Any new flavor encountered during recovery from a digestive illness will acquire a pleasant affective tone [56]. This process may explain certain positive idiosyncrasies, just as the Garcia effect can explain some negative idiosyncrasies [6]. Another example involves monetary gain.

\section{Money}

Researchers have found that people require more money to give up an item than they are willing to pay for that same item [57]. Thus, the value of money is variable [58]. In other words, the hedonicity associated with an amount of money varies, simply reflecting the pleasure felt by holding on to it. However, the pleasure it brings can be lowered when compared with the pleasure of the acquired item $[7,8,46,50]$. Also, the pleasure experienced from money was found to vary when pitted against muscular fatigue or thermal discomfort, thus another sign of alliesthesia associated with money.

\section{Play}

Human subjects found that playing games become more enjoyable, i.e. alliesthesia, when the desired result was obtained more quickly [59].

\section{Other senses anddecisions}

When presented with a questionnaire regarding the hedonicity of winning and losing bets, the ensuing behavioral choices showed that changes in hedonic outcomes explained real-life choices. The actual decisions in favor of the selected outcomes tended to maximize pleasure [60], indicating a change in hedonicity, i.e. a kind of alliesthesia criteria.

\section{Grammar}

Study of linguistic theories has found that grammar may correspond to some kind of optimal functioning of the nervous system [61]. In a second language grammar test, pleasure ratings coincided with the right or wrong choices that subjects subsequently made. The close relationship between choice and pleasure rating confirm both the Prince-Smolensk hypothesis and the hypothesis that pleasure optimize mental functioning in the same way that it optimizes physiological functioning. The optimization of mental functioning, indicated by the perception of pleasure, is also suggested in the results of experiments involving video-game playing and poetry reading [62].

\section{Ethical decision-making and aggressiveness}

"A morality is a system of principles and values concerning people's behavior, generally accepted by a society or by particular group of people" [63]. Although decision-making and mental pleasure may coincide in questionnaires when the questions are grammatical or mathematical, the overlap shrinks when the questions are based on moral imperatives. When asked after a multiple-choice test, participants acknowledged that they had chosen more pleasurable answers, even though immoral ones [64]. Ethics was shown to produce a negative alliesthesia towards meat eating because meat that provides pleasure to many people also causes animals to suffer. This so-called "meat paradox" produces feelings of discomfort towards the pleasure of eating meat [65].

"The search for pleasure is at the heart of any violent action." "It is a pleasure to avenge oneself. Who would disagree?" [66]. The pleasure or displeasure generated by aggressive solutions to minor social conflicts were rated in multiple choice questionnaires by control subjects [67] and by incarcerated criminals [68]. The aggressive solutions were rated unpleasant when they ended in passive or peaceful responses and as pleasant when they ended in a fairly aggressive manner. Indeed, pleasure is activated when unpleasant events occur to people we dislike [69]. Aggressive behavior is by nature only transient, meaning that it is also a response to alliesthesia. 


\section{Politics}

It is of interest to look at the domain of government and politics from the hedonic point of view, because these are areas where important decision are made everyday [70]. Experimental results have shown that pleasure influences political decisions [71] and as any public media will confirm, politics tend to change with variations in electoral hedonicity rather than with rationality, resulting in alliesthesia.

\section{Learning and Memory}

What is the source of all human knowledge? Experimental results showed that acquisition of knowledge is a deeply rooted psychological need, a motivational mechanism, involving hedonicity, for perception as well as higher cognition. The satisfaction of curiosity, through acquiring knowledge brings pleasure. By its very nature satisfaction is alliesthesia. This confirms the hypothesis that curiosity or the need for knowledge is a fundamental and ancient motivation on a par with other basic needs, such as sex or food. This shows that curiosity operates on hedonic variations (i.e. alliestesia) similarly as knowledge, and cognition.

\section{Animals}

One may expect that as soon as consciousness evolved [72], animal behavioral response ceased to be exclusively reflexive and relied mostly on hedonic experience and alliesthesia.

While humans can talk and describe their cognitions and hedonic feelings, evidence of hedonic experience in animals can only be obtained from the reward sought in experiments on operant behavior learning with motor responses. Yet, that evidence has been gained also from two specific responses: rat's facial expressions and the exceptional case of a speaking bird [73]. Rats' expressions and body gestures show the animal's pleasure and, like humans, alliesthesia for gustatory sensations [74]. A rat's facial expressions are also influenced by its ponderostat set-point in ways similar to those of humans [75]. These responses showed that rats, like humans, experience positive alliesthesia $[76,77]$ for water [78], salt [13] and sweetness [79-81]. In pigs palatability estimated through consumption patterns of sucrose or glutamate stimuli (consumption time/approaches; CT/A), facial expressions (snout openings and tongue protrusions) and consumption during a brief 2 min period, showed variable facial expression and consumption to these stimuli [82].

Also in rats, positive alliesthesia occurs in sensations from aversive taste stimuli when associated with intake of sugar or nutrients [83]. As alliesthesia reflects the fluctuating physiological and or mental demands in a conscious animal, the satiation of any sensory stimulus is likely to be associated with sensory alliesthesia. Similarly, when a given ambiant temperature is sought or avoided, it may be hypothesized that the welfare of animals depends on their ability to spend stored energy in order to survive the changing environmental and behavioral challenges at any particular time. Such a mechanism is an example of life-long alliesthesia, seeing as a given body mass index adopts a different meaning depending on the environment [84]. Therefore, the alliesthesia found in mammals would entail that human alliesthesia was phylogenetically inherited for its Darwinian usefulness [34]. In defending both ponderostat and A thermostat, animal alliesthesia parallels so closely human taste sensations so closely $[85,86]$, that it has been proposed as a criterion for the moments when satiation centers activate in the brain and that it allows to analyze the CNS structure of the neural paths and centers activated whenever a pleasant or unpleasant taste is being experienced.

Animal studies permit an invasive exploration of the brain, i.e. recording of action potentials, stimulations, and lesions. The anatomy of brain centers for motivation [87], provided some indirect evidence of alliesthesia. Although a very broad field in the whole brain may be associated to hedonicity [88], interest has focused on the nucleus accumbens involved in feeding motivation and the hedonics of taste sensation [89]. Its activation, when paired with a reinforce such as a drug, acquires then the capacity to motivate behavior [90]. The amygdala and the hippocampal complex are involved as two independent memory systems. They activate memory in emotional situations, cognition with a major role in needed time-dependent hedonicity [91].

When pleasure from all sensory inputs may, at least occasionally, not only enhance subsequent consumption, but also prompts animals to seek anything rewarding including petting [71] and massage [92], alliesthesia may be considered to be the universal animal motivator of behaviors and decisions in those animals gifted with consciousness. From such phylogenic probability it may be hypothesized that alliesthesia is present in humans not only from the five senses but universally. It could be a fundamental way phylogenetically inherited to optimize behavior taking place in all responses to sensory messages and in all human decisions whatever the motivation, the input pathway or the resulting behavior.

\section{Decision making}

There are innumerable coexisting motivations behind the quest for behavioral satisfaction. As McFarland pointed out in human behavior [93], all motivations in animals also must be able to dialogue in order to rank the importance of each situation. The hedonic dimension of mental experience has been offered as such common currency [94]. One may accept that it is not only pleasure but rather alliesthesia, i.e. adaptable hedonicity, that occur in all mental processes, from simple sensations to the most complex decision-making processes, as seen in many experiments reported above. 


\section{A new definition of the word Alliesthesia}

The acknowledgement that alliesthesia is not limited to simple physiology (temperature and food sensations), led to explore its function in other sensations. Experimental evidence has shown that alliesthesia may occur at the service of all physiological setpoints. Thus, although alliesthesia was initially established - even in animals- in single sensations and then in a whole-body complex of combined sensations, alliesthesia has also been identified in non-sensory cognitions and in all mental cognition. This has led to the conclusion that alliesthesia plays a major role in decision making, whatever the field of decision and extends to ethical and perhaps even religious decision-making processes. It follows that alliesthesia can be accepted as the fundamental mental mechanism of cognition and decision making, probably phylogenetically inherited for it efficacy in producing useful behaviors and its ability to promote comfort and happiness [8]. Such a conclusion leads to the deduction that the initial definition of Alliesthesia as purely sensory is now obsolete and no longer appropriate to describe alliesthesia. Therefore, a new definition for alliesthesia is suggested (Figure 2).

Alliesthesia refers to a modified outcome or rise in the hedonic dimension of any mental

process, from sensation to mental performance, and decision making, leading to

physiological comfort and happiness. Positive alliesthesia is the rise in pleasure, or joy,

and a decrease in displeasure or pain. Negative alliesthesia is the opposite.

Figure 2: The new definition for Alliesthesia.

\section{Acknowledgements}

The authors give special thanks to M, Horowitz, T. Nagazaka, S. Nicolaidis, N. Ovsich and S. Rankin for their kind semantics helps.

\section{References}

1. Cabanac M (1971) Physiological role of pleasure. Science 173(4002): 1103-1107.

2. (2011) Alliesthesia. Segen's Medical Dictionary, Farlex, Inc.

3. Rolls BJ, Rolls ET, Rowe EA, Sweeney K (1981) Sensory specific satiety in man. Physiol Behav 27(1): 137-142.

4. Garcia J, Lasiter PS, Bermudez-Rattoni F, Deems DA (1985) A general theory of aversion learning. Ann NY Acad Sci 443: 8-21.

5. Perlovsky L, Cabanac A, Bonniot-Cabanac, MC, Cabanac M (2013) Mozart effect, cognitive dissonance, and the pleasure of music. Behav Brain Res 244: 9-14.

6. Morewedge CK (2015) Utility: Anticipated, experienced and remembered. In G. Keren \& G. Wu (Eds.). The Wiley black well handbook of judgment and decision making 1: 295-330.

7. Whalen RE (1959) Analysis of species-specific behavior as exemplified by sexual patterns. Paper presented at the 39th Annual Meeting of the Western Psychological Association, San Diego, CA.

8. Cabanac M (2000) What is happiness? Paper presented at the Fechner Day 2000, International Society for Psychophysics, Strasbourg.
9. Katz-Salamon M (1984) Ability to judge lung volumes at different co2drives for ventilation and the possible influence of such a judgment on the ventilatory co2-responsiveness. Acta PhysiolScand 120(2): 177-183.

10. Ovsich AJ (2017) Mathematical models of desire, need, attention, and will effort. In J Vallverdú, M Mazzara, M Talanov, S Distefano \& R Lowe (Eds.) Advanced research on biologically inspired cognitive architectures pp. 177-213.

11. Khazaal Y, Chatton A, Claeys F, Ribordy F, Zullino D, et al. (2008) Antipsychotic drug and body weight set-point. PhysiolBehav 95(1-2): 157-160.

12. Hubbard RW, Sandick BL, Matthew WT, Francesconi RP, Sampson JB, et al. (1984) Voluntary dehydration and alliesthesia for water. J Appl Physiol Respir Environ ExercPhysiol 57(3): 868-873.

13. Cabanac M, Duclaux R (1973) [olfactory-gustatory alliesthesia and food intake in humans]. J Physiol (Paris) 66(2): 113-135.

14. Richter CP (1936) Increased salt appetite in adrenalectomized rats. Am J Physiol 115: 155-161.

15. Jiang T, Soussignan R, RigaudbD, Martin S, Royet JP, et al. (2008) Alliesthesia to food cues: Heterogeneity across stimuli and sensory modalities. Physiol. Behav 95(3): 464-470.

16. Maille EL (2011) Récepteursgustatifs des moléculessucrantes et antisucrantes - un rôlemétaboliqueinsoupçonné. Med. Sci. (Paris) 27: 177-182.

17. Cines BM, Rozin P (1982) Some aspects of the liking for hot coffee and coffee flavor. Appetite 3(1): 23-34

18. Cabanac M, Ferber C (1987) Pleasure and preference in a twodimensional sensory space. Appetite 8(1): 15-28.

19. Ikeda K (1909) On a new seasoner. J Tokyo Chem Soc 30: 820-836.

20. Fantino M, Brinnel H (1986) Body weight set-point changes during the ovarian cycle: Experimental study of rats using hoarding behavior. PhysiolBehav 36(6): 991-996.

21. Clarke SN, Ossenkopp KP (1998) Taste reactivity responses in rats: Influence of sex and the estrous cycle. Am J Physiol 274(3): R718-R724.

22. Gray RW, Cooper SJ (1996) D-fenfluramine's effects on normal ingestion assessed with taste reactivity measures. Physiol. Behav 59(6): 11291135.

23. Fantino M, Faion F, Rolland Y (1986) Effect of dexfenfluramine on body weight set-point: Study in the rat with hoarding behaviour. Appetite 7: 115-126.

24. Lucas RE (2007) Adaptation and the set-point model of subjective wellbeing: Does happiness change after major life events? Curr Dir Psychol Sci 16(2): 75-79.

25. Le Magnen J (1953) Activité de l'insuline sur la consommationspontanée des solutions sapides. CR Seances SocBiol Fil 147: 1753-1756.

26. de Guglielmo, G, Kallupi M, Cole MD, George O (2017) Voluntary induction and maintenance of alcohol dependence in rats using alcohol vapor self-administration. Psychopharmacology (Berl) 234(13): 20092018.

27. Ramsay DS, Kaiyala KJ, Woods SC (2014) Correctly identifying responses is critical for understanding homeostatic and allostatic regulation. Temperature (Austin) 1(3): 157-159.

28. Rainville P, Carrier B, Hofbauer RK, Bushnell MC, Duncan GH (1999) Dissociation of sensory and affective dimensions of pain using hypnotic modulation. Pain 82(2): 159-171.

29. Cabanac M (1986) Money versus pain: Experimental study of a conflict in humans. J Exp Anal Behav 46(1): 37-44.

30. Chen B, Jones, NL, Killian K J (1999) Is there a conflict between minimizing effort and energy expenditure with increasing velocities of muscle contraction in humans? J Physiol 518 (Pt 3): 933-940. 
31. Cabanac M, Leblanc J (1983) Physiological conflict in humans: Fatigue vs. Cold discomfort. Am J Physiol 244(5): R621-R628.

32. Ekkekakis P (2003) Pleasure and displeasure from the body: Perspectives from exercise. CognEmot 17(2): 213-239.

33. Ekkekakis P, Hall EE, Petruzzello SJ (2004) Practical markers of the transition from aerobic to anaerobic metabolism during exercise: Rationale and a case for affect-based exercise prescription. Prev Med 38(2): 149-159.

34. Ekkekakis P, Hall, EE, Petruzzello SJ (2005) Variation and homogeneity in affective responses to physical activity of varying intensities: An alternative perspective on dose-response based on evolutionary considerations. J Sports Sci 23(5): 477-500.

35. SokE (2018) The role of alliesthesia in building design.

36. Mineka S, Keir R, Price V (1980) Fear of snakes in wild-reared and laboratory-reared rhesus-monkeys (macaca-mulatta). Anim. Learn. Behav 8(4): 653-663.

37. Johnston VS (1999) Why we feel: The science of human emotions. Cambridge, MA: Perseus Books.

38. Brondel L, Cabanac M (2007) Alliesthesia in visual and auditory sensations from environmental signals. PhysiolBehav 91(2-3): 196-201.

39. Green DM (1988) Psychophysics and perception Stevens' handbook of experimental psychology (2th ed) 1: 327-376.

40. OvsichA J (1998) Outlines of the theory of choice: Attitude, desire, attention, will. Paper presented at the The Paideia project : Twentieth World Congress of Philosophy, Boston, MA.

41. Huffman EK, Chabris CF, Arily D, Aharon I, Kaplan LM, et al. (2006) Pictures of food have reward value that varies according to appetitive state.

42. Russell JA, Fehr B (1987) Relativity in the perception of emotion in facial expressions. J Exp Psychol (General) 116(3): 223-237.

43. Changizi MA, Hall WG (2001) Thirst modulates a perception. Perception 30(12): 1489-1497.

44. Kim SH, Tokura H (1998) Visual alliesthesia-cloth color preference in the evening under the influence of different light intensities during the daytime. PhysiolBehav 65(2): 367-370.

45. Aharon I, Etcoff N, Ariely D, Chabris CF, O’Connor E, et al. (2001) Beautiful faces have variable reward value: Fmri and behavioral evidence. Neuron 32(3): 537-551.

46. Agmo A (1999) Sexual motivation--an inquiry into events determining the occurrence of sexual behavior. Behav Brain Res 105(1): 129-150.

47. He FQ Yu P, Wu RY (2013) Relationship between sexual satiety and motivation, brain androgen receptors and testosterone in male mandarin voles. Behav Brain Res 250: 257-263.

48. Le Magnen J (1952) [olfactory-sexual phenomena in man]. ArchSci Physiol (Paris) 6(2): 125-160.

49. Doty RL, Ford M, Preti G, Hugginsm GR (1975) Changes in the intensity and pleasantness of human vaginal odors during the menstrual cycle. Science 190(4221): 1316-1318.

50. Clarke SN, Ossenkopp KP (1998) Hormone replacement modifies cholecystokinin-induced changes in sucrose palatability in ovariectomized rats. Peptides 19(6): 977-985.

51. Romano-Torres M, Phillips-Farfan BV, Chavira R, Rodriguez-Manzo G, Fernandez-Guasti A (2007) Relationship between sexual satiety and brain androgen receptors. Neuroendocrinology 85(1): 16-26.

52. Tversky A, Kahneman D (1981) The framing of decisions and the psychology of choice. Science 211(4481): 453-458.

53. Perlovsky L, Bonniot-Cabanac MC, Cabanac M (2010) Curiosity and pleasure. Webmed Central Psychology 1(12): WMC001275.
54. Manolika M,Baltzis A (2019) Curiosity's pleasure? Exploring motives for cultural consumption. Int J Nonprofit Volunt Sect Mark, e1640.

55. Berridge KC (2000) Reward learning: Reinforcement incentives and motivation Psychol. Learn Motiv 40: 223-278.

56. Garcia J, Kimeldorf DJ, Koelling RA (1955) Conditioned aversion to saccharin resulting from exposure to gamma radiation. Science 122(3160): 157-158.

57. Baron J (1994) Nonconsequentialist decisions. Behav Brain Sci 17(1): $1-10$.

58. Knetsch JL, Sinden JA (1984) Willingness to pay and compensation demanded: Experimental evidence of an unexpected disparity in measures of value. QJEcon 99(3): 507-521.

59. Hsee CK, Abelson RP (1991) Velocity relation: Satisfaction as a function of the first derivative of outcome over time. J. Pers. Soc. Psychol 60(3): 341-347.

60. Cabanac M (1989) Maximization of pleasure, the answer to a conflict of motivations. C R Acad Sci III 309(10): 397-402.

61. Prince A, Smolensky P (1997) Optimality: From neural networks to universal grammar. Science 275(5306): 1604-1610.

62. Balasko M,Cabanac M (1998) Grammatical choice and affective experience in a second-language test. Neuropsychobiology 37(4): 205210.

63. Cobuilt, Collins (Ed.) (1993) English language dictionary. London.

64. Cabanac M, Guillaume J, Balasko M, Fleury A (2002) Pleasure in decisionmaking situations. BMC Psychiatry 2.

65. Buttlar B, Walther E (2019) Dealing with the meat paradox: Threat leads to moral disengagement from meat consumption. Appetite 137: 73-80.

66. Lévy T (1984) Le crime entoutehumanité. Paris: Figures Grasset.

67. Ramírez JM, Bonniot-Cabanac MC, Cabanac M (2005) Can aggression provide pleasure? Eur Psychol 10: 136-145.

68. Ramirez JM, Millana Cuevas LC, Toldos Romero MP, Bonniot-Cabanac MC, Cabanac M (2009) The pleasure of being aggressive in male incarcerated criminals. Open Criminol J: 2: 1-9.

69. Takahashi H, Kato M, Matsuura M, Mobbs D, Suhara T, Okubo Y (2009) When your gain is my pain and your pain is my gain: Neural correlates of envy and schadenfreude. Science 323(5916): 937-939.

70. Bonniot-Cabanac MC, Cabanac M (2010) Do government officials decide more rationally than the rest of us? Soc Behav Pers 38(8): 1147-1152.

71. Cabanac M (2009) Do birds experience sensory pleasure? Evol PsycholUs $7(1): 40-47$.

72. Cabanac M, Cabanac AJ, Parent A (2009) The emergence of consciousness in phylogeny. Behav Brain Res 198(2): 267-272.

73. Pepperberg I (1990) Some cognitive capacities of an african grey parrot (psittacuserithacus). In PJB slater, JS Rosenblatt \& C. Beer (Eds.), Advances in the study of behavior 19: 357-409.

74. Grill HJ, Norgren R (1978) Chronically decerebrate rats demonstrate satiation but not bait shyness. Science 201(4352): 267-269.

75. Cabanac M, Lafrance L (1991) Facial consummatory responses in rats support the ponderostat hypothesis. PhysiolBehav 50(1): 179-183.

76. Berridge KC, Grill HJ (1984) Isohedonic tastes support a two-dimensional hypothesis of palatability. Appetite 5(3): 221-231.

77. Cabanac M, Lafrance L (1992) Duodenal preabsorptive origin of gustatory alliesthesia in rats. Am J Physiol 263(5 Pt 2): R1013-R1017.

78. Scalera G (2000) Taste preference and acceptance in thirsty and rehydrated [correction of dehydrated] rats. PhysiolBehav 71(5): 457468. 
79. Bedard M, Weingarten HP (1989) Postabsorptive glucose decreases excitatory effects of taste on ingestion. Am J Physiol 256(5 Pt 2): R1142-R1147.

80. Cohen PS, Tokieda FK (1972) Sucrose-water preference reversal in the water-deprived rat. J Comp Physiol Psychol 79(2): 254-258.

81. Le Magnen J (1955) [the role of the gustatory receptivity to sodium chloride in the mechanism of regulation of water intake in the white rat]. J Physiol (Paris) 47(2): 405-418.

82. Figueroa J, Frias D, Sola-Oriol D, Tadich T, Franco-Rossello R, et al. (2019) Palatability in pigs, the pleasure of consumption1. J Anim Sci 97(5): 2165-2174.

83. Mehiel R, Bolles RC (1988) Hedonic shift learning based on calories. B Psychonomic Soc 26(5): 459-462.

84. Cabanac AJ (2003) Physical condition of an animal, using as an example the common elder, somateriamollissima. Can Field Nat 117(2): 230-235.

85. Scalfani A (1991) The hedonics of sugar and starch. R Bolles (Ed) The hedonics of taste (59-82). Hillsdale: Lawrence Erlbaum Associates, Inc.

86. Schulkin J (1991) Hedonic consequences of salt hunger. In RBolles (Ed) The hedonics of taste (89-105). Hillsdale: Lawrence Erlbaum Associates, Inc.

87. Shizgal P (1997) Neural basis of utility estimation. CurrOpinNeurobiol $7(2): 198-208$.
88. Allen WE, Chen MZ, Pichamoorthy N, Tien RH, Pachitariu M, et al. (2019) Thirst regulates motivated behavior through modulation of brainwide neural population dynamics. Science 364(6437): 253.

89. Pecina S, Berridge KC (2000) Opioid site in nucleus accumbens shell mediates eating and hedonic 'liking' for food: Map based on microinjection fos plumes. Brain Res 863(1-2): 71-86.

90. Cardinal RN, Everitt BJ (2004) Neural and psychological mechanisms underlying appetitive learning: Links to drug addiction. Curr. Opin. Neurobiol 14(2): 156-162.

91. Phelps EA (2004) Human emotion and memory: Interactions of the amygdala and hippocampal complex. CurrOpinNeurobiol 14(2): 198202.

92. Wadhwa M, Shiv B, Nowlis SM (2008) A bite to whet the reward appetite: The influence of sampling on reward-seeking behaviors. J Marketing Res 45(4): 403-413.

93. McFarland DJ, Sibly RM (1975) The behavioural final common path. Philos. Trans R Soc Lond B Biol Sci 270(907): 265-293.

94. Cabanac M (1992) Pleasure: The common currency. J Theor Biol 155(2): 173-200.

95. Cabanac A (2017) Arts and scholastic performance. Creative Education 8: 2393-2399.

96. Cabanac M (2009) Pleasure in decision-making situations: Politics and gambling. J Risk Res 12(5): 619-645. 